\title{
Cultivating a Community of Practice through Podcasting
}

Gregory M. Zumach, PharmD, BCPS ; Edward Portillo, PharmD ${ }^{2}$

${ }^{1}$ Oregon State University College of Pharmacy; ${ }^{2}$ University of Wisconsin-Madison School of Pharmacy

\begin{abstract}
While innovation in pharmacy education can be sparked through many avenues, the opportunity to learn and engage with others through practice communities is considered by many as a creative outlet for exchange and discovery. This commentary specifically describes a contemporary approach to promote such a dialogue globally through podcasting, which is a free and highly accessible medium for dissemination and exchange of innovative teaching practices. In 2018, two faculty from two colleges of pharmacy created a podcast titled Leadership Development in Pharmacy Education (LDPEcast), which provides a unique modality to stimulate discussion and disseminate ideas within the community of practice. This commentary provides a case illustration for how a podcast can be intentionally designed and implemented with the goal of inspiring engagement across a global practice community. Early results of the podcast have been largely successful with nearly 1000 episode downloads and an additional 445 episode streams from audience members. While this podcast was designed specifically to discuss leadership integration within pharmacy training, opportunities may exist for further exploration of podcasting to spread innovative ideas, practices, and evaluative approaches in pharmacy education, while strengthening connections and elevating communities of practice across institutions.
\end{abstract}

Keywords: Communities of practice, leadership, pharmacy education, podcast

\section{Background}

As pharmacy educators, we are uniquely positioned to advance the pharmacy profession through effective teaching, scholarship, and service initiatives. The changing landscape of pharmacy practice demands not only that new, pharmacistdriven models of care be developed, but also that students are empowered to think both creatively and strategically to promote such positive change as pharmacy leaders. Given the importance of our work in shaping the leadership skill-set of future pharmacists, our ability to share ideas, best practices, and collaborate is critical. This commentary challenges the academy to consider an innovative approach to collaboration through podcasting. We view podcasting as a novel opportunity to cultivate strong communities of practice centered on leadership education. Most importantly, the ability to share ideas and collaborate through podcasting is free, fun, and full of opportunity to spark a far-reaching conversation.

Podcasting is defined as "a broadcast that is placed on the internet for anyone who wants to listen or watch it". ${ }^{2}$ From 2014 to 2017 , there has been an $88 \%$ increase in the number of individuals who listen to weekly podcasts, with anticipation that podcasting as a medium of communication will only continue to rapidly increase.,4 The uses of podcasting have been widespread, with over 500,000 podcasts on the Apple platform alone, ranging from arts to business, education, science, TV, and film. ${ }^{5}$ While within higher education podcasting has been evaluated extensively as a method to enhance student

Corresponding author: Gregory M. Zumach, PharmD, BCPS

Oregon State University College of Pharmacy

1601 SW Jefferson Ave, 203 Pharmacy Bldg.

Corvallis, Oregon 97331

Email: gregory.zumach@oregonstate.edu learning, ${ }^{6,7}$ there are only limited examples in the literature regarding the use of podcasting with the intent to strengthen communities of practice within the pharmacy profession. Incorporating podcasting as a method to enhance communication is described by Eib and Miller $^{8}$ as a future opportunity in their work illustrating faculty development and connectedness. However, to the authors' knowledge, there are limited descriptive examples of approaches to employing podcasting, specifically for a community of practice in higher education.

\section{Designing a Podcast to Support a Community of Practice}

The core tenets of podcasting are well aligned to promote Communities of Practice (CoP), which are defined by Wenger and Lave as "groups of people who collectively deepen their knowledge and expertise in an area through frequent interaction". ${ }^{9}$ Communities of Practice have many unique qualities, but may be best defined by the passion and dedication of those who self-select to participate. Podcasting, like communities of practice, has the potential to reach a large, passionate audience across organizations, states, and even countries. Both podcasting and communities of practice emphasize the discovery of knowledge rather than the delivery of products, services, or tasks. Additionally, podcasting and communities of practice are each effective avenues to promote leadership development in pharmacy education.

Communities of Practice, when effectively cultivated, are defined by Wenger et al. by their "aliveness," which encompasses the organic excitement, discussion, and flexibility among members eager to collectively deepen their knowledge. Authors of this commentary have developed a podcast, titled Leadership Development in Pharmacy Education podcast (LDPEcast), which was intentionally designed to complement and broaden discussion within the Leadership Development 
Special Interest Group (LDSIG) at American Association of Colleges of Pharmacy (AACP). However, through the expansion and growth of the podcast, listeners and podcast subscribers have expanded well beyond the AACP membership base. This is consistent with one of the key aspects of communities of practice, which are fluid, with limited borders and opportunities to grow. This is the first podcast in existence within AACP, and it is a goal for this communication medium to reach a large, dynamic, and passionate audience of individuals focused on deepening their knowledge in leadership education. The inclusive nature of the content and being publically available allows audience members to participate both inside and outside of the academy and globally.

When initially designing LDPEcast, co-hosts felt it was critical to consider the specific goals and interests of listeners. The LDSIG's core mission is to support the development of leaders in all facets of the Academy and the profession of pharmacy, with an emphasis on exchange of ideas and resources to prepare faculty, students, preceptors, and practitioners to be leaders and change agents. Working to support the core mission, the goal of LDPEcast is to create a space for conversations centered on leadership development in pharmacy education, with the goal of identifying best practices in the field and increasing the adoption of novel approaches in leadership curriculum design. Podcast co-hosts rely heavily on collaboration within the LDSIG to identify guest content experts. The core tenets of LDPEcast are described below within each of the seven principles described by Wenger to cultivate a community of practice (Table 1$).^{9}$

\section{Design for Evolution}

Designing LDPEcast for evolution involved both considerations of content delivery and technical coordination. The original content and inception of LDPEcast started with an organic idea by two faculty members passionate about leadership development within pharmacy curricula. True to a community of practice, it was a shared passion for leadership development in pharmacy education that sparked the collaboration, and the eventual launch of LDPEcast. Designing a podcast to embrace change, new ideas, and to provide space for exploration and discovery was key. In a sense, designing LDPEcast for evolution required a true desire not to plan ahead or be overly detailoriented, but rather to embrace the concept of open-space to spotlight the immense creativity, diversity of ideas, and exploration of aspects of leadership education that may have not yet been published in the literature. Similar to a community of practice, LDPEcast was designed to evolve, to change, and to serve as a listener-driven current for innovative ideas in pharmacy leadership education.

Technical considerations were also explored early in podcast development to plan for growth. Decisions were made that would allow for an eventual increase in audience size, the number of downloads, plays, episodes and also free podcast subscriptions. Research of successful podcasts at aspirational levels of media participation were analyzed. Additionally, it proved vital to review so-called Dos and Don'ts webpages for general recommendations for starting a podcast. ${ }^{10}$ This research began approximately six weeks prior to the first episode release. As with any project, cost became a key factor. There are a considerable number of free and inexpensive options available for host software, recording programs, and devices. The creators ultimately decided to devote more financial resources to hosting sites that provided added bandwidth and digital storage, while using free audio software and manually performing post-production on all episodes. Making this decision early on provided a higher ceiling of media participation. Though not an original goal of the creators, LDPEcast has now become an international podcast with episode plays from the United States, Canada, Italy, Spain, and Ghana.

\section{Open a Dialogue between Inside and Outside Perspectives}

The concept of expanding knowledge through obtaining an outside perspective is a central tenet of any community of practice. The models, theories, and frameworks centered on leadership development have broad applicability, and their use extends well beyond pharmacy education. As such, podcast guests may not be a member of the leadership development interest group where the podcast is formally housed. The primary requirement for guest presenters is that their unique leadership development experience, perspective, and expertise can be shared with the broader audience. Through casting a broad net for engagement of both guests and participants, LDPEcast co-hosts strive to diversify ideas and identify best practices that may have yet to be discussed.

In addition to inviting podcast guests with diverse skill sets and experiences, podcast discussion topics are also selected based on input from a broad audience. Prior to initial episode development, key stakeholders were identified and contacted to provide initial feedback on potential episode topics. These stakeholders included current executive council members from the LDSIG, a manager of member engagement of the AACP parent organization, and other individuals who might be future audience members but were not necessarily members of AACP. Incorporating both an inside and outside perspective allows a wider range of topics to be featured.

\section{Invite Different Levels of Participation}

Opportunities for engagement within LDPEcast have been intentionally designed to fit the specific needs of the individual, with the understanding that each listener may have a unique goal or purpose for subscribing. The concept of having different opportunities, or avenues, of engagement, is a critical element of any community of practice. Wenger et al. describe participation at three levels: (1) at the periphery, (2) through active engagement, or (3) as a core group member. ${ }^{9}$ Given the delivery modality of podcasting, many subscribers may elect to participate at the periphery. Podcast co-hosts view peripheral engagement as incredibly valuable, and these individuals are 
considered critical to the community of practice. It is these individuals that may be incorporating leadership content discussed in their classrooms or workplaces to promote the development of leaders both within and outside of the pharmacy profession.

Active engagement is also encouraged to help stimulate the conversation, and this is completed by posing discussion questions to the larger audience on the AACP Connect interactive web page, as well as through social media platforms. Podcast co-hosts have been encouraged by the many discussions that occurred through email dialogue and social media, which have then inspired generation of new podcast episodes. Several episodes are set to be released featuring guests based on feedback from audience members.

As the podcast has matured, a sub-committee of core community of practice members has been put in place to participate in the activities of the podcast. This includes coordination of guests, research into leadership topics, and engagement within social media. The authors plan to further include members of the sub-committee as guests on future episodes of the podcast.

\section{Develop Both Public and Private Community Spaces}

Podcasts utilize digital mediums and communities of the podcast are likewise digital in nature. It's impossible to create community space in digital mediums and not develop a heavy connection to social media platforms. A Twitter account (@LDPEcast) was created to help announce episodes, while also interacting with audience members. Since certain members of the audience are or were not members of AACP when episodes of the podcast were initially released, the Twitter account has proven to be a successful medium to increase audience numbers.

In addition, AACP Connect is a member-based digital platform that hosts interest groups. It allows the announcement of episodes, sharing of ideas, ongoing dialogue between listeners and another venue for providing feedback to the hosts.

\section{Focus on Value}

The true value of LDPEcast is held within its subscribers, and how content is disseminated, adapted, and adopted to enhance the leadership learning experience for student pharmacists. Potential topic identification was therefore driven first and foremost by whether the discussion would be value-added to the pharmacy educator audience and ideally the leadership development community at large. The majority of topics featured in episodes involve guests who have participated in leadership development initiatives through the LDSIG community. For example, guests have written reviews for the AACP Book Blog and been participants in the Leadership Development Virtual Symposium. Not only did each of these larger projects include topics that were pertinent to the goals of the podcast, but by driving interest from podcast listeners back to the Book Blog and Virtual Symposium, the podcast added additional support to these endeavors of the LDSIG.

Furthermore, the goal length of each LDPEcast episode is 12-15 minutes, which is intentional to allow listeners to engage in content during available moments in their day, such as a morning commute. In addition, the LDPEcast is readily available on numerous devices and applications where podcasts can be downloaded, including Apple Podcast, Spotify, and Podomatic. The ability for listeners to easily access content and incorporate the podcast into their daily routine allows for a greater content reach to a broad array of listeners.

\section{Combine Familiarity and Excitement}

While developing initial episode topics, it was critical to identify dynamic content experts to serve as guests, while also challenging subscribers to consider new approaches to incorporate leadership in the classroom. Therefore, initial guests spoke to a variety of topics, but also a specific, unique approach to leadership instruction, whether through the application of a specific leadership framework, program, course, or activity. It was the hope of LDPEcast co-hosts that this combination of familiar speakers and topics, along with potentially unfamiliar leadership content would spark excitement among subscribers.

\section{Create a Rhythm for the Community}

When researching successful podcasts, consistency was identified as a key feature in podcasts that developed a following and ultimately exhibited growth. ${ }^{10}$ This focus on consistency has been reflected in feedback from listeners as positive. In particular, audience participants have noted an appreciation for the frequent podcast episodes release (every other week) and for the consistent time of each episode (approximately 12-15 minutes in length). Due to the varied nature of leadership, content can revolve around many different topics, however, the creators ensure that each episode has the primary focus on addressing leadership development in pharmacy education.

\section{Future Directions}

To improve communication and foster greater discussions within the CoP, the co-hosts plan to incorporate consistent processes for engaging with listeners using assistance from LDSIG sub-committee members. Production procedures in particular can be further enhanced with the support of LD SIG committee members, which can allow for greater promotional materials for upcoming episodes, as well as posting of discussion questions

Given the many opportunities for leveraging this communication modality, the full benefits of podcasting to promote dialogue within our community of practice has yet to be recognized. The special interest group that houses LDPEcast includes nearly 1000 members, making this one of the largest special interest groups within AACP. Opportunities exist for 
LDPEcast to further increase in free subscriptions, which can be completed through the increased promotion of the podcast using social media and through word of mouth across various schools and colleges of pharmacy. The opportunity also exists to leverage LDPEcast as a mechanism to increase awareness at schools and colleges of pharmacy regarding the importance of leadership development within Doctor of Pharmacy curricula. The ease of accessing podcast episodes, along with the minimal time-commitment required to engage in podcast content, could help expand the podcast's message to listeners globally.

Finally, additional engagement of LDPEcast with other special interest groups within the parent organization is a central goal over the next year. For example, episodes are currently available with invited guests from other SIGs, including the Women's Faculty SIG, Curriculum SIG, and the Global Pharmacy Education SIG. Through these initiatives, LDPEcast can serve as an example of communities of practice serving as stewards of knowledge through various mechanisms of dialogue, discussion, and dissemination of information. Many guests on the podcast are excited about continuing the leadership conversation with interested listeners during follow-up phone calls or email outreach. The opportunity for listeners to be engaged with a specific leadership topic, learn about a case example of how that topic has been applied within pharmacy education, and easily contact a colleague with first-hand experience provides a unique opportunity to connect colleagues across institutions, states, and even countries to spark new conversations and collaborations surrounding leadership.

\section{References}

1. Podomatic.com. (2019). Create a Podcast $>>$ Start Podcasting | Hosting by Podomatic. [online]. Leadership Development in Pharmacy Education. Available at:

https://www.podomatic.com/podcast/pro_stats/ [Accessed 6 Jan. 2020].

2. Dictionary.cambridge.org. (2019). PODCAST | definition in the Cambridge English Dictionary. Available at:

https://dictionary.cambridge.org/us/dictionary/englis h/podcast. Accessed October 2, 2019.

3. Zorn E. Listen up - again! The podcast boom is just getting started. Chicago Tribune February 16, 2018. https://www.chicagotribune.com/columns/ericzorn/ct-perspec-zorn-podcasting-boom-revolutionaudio-0218-20180216-story.html. Accessed September 26, 2019.

4. Revzin S, Revzin V. Podcast Trends In 2019 That You Should Know About. Forbes. https://www.forbes.com/sites/sergeirevzin/2019/03/ 21/podcast-trends-in-2019-that-you-should-knowabout/\#1c54704453e8. Published March 21, 2019. Accessed October 2, 2019.

5. Misener D. These are the most crowded categories in Apple Podcasts. Medium. https://blog.pacificcontent.com/the-most-crowded-categories-in-applepodcasts-7123447660cf. Published October 11, 2018. Accessed October 2, 2019.

6. Fernandez V, Simo P, Sallan JM. Podcasting: A new technological tool to facilitate good practice in higher education. Computers \& Education. 2009;53(2):385392. doi:10.1016/j.compedu.2009.02.014

7. Flood M, Hayden JC, Bourke B, Gallagher PJ, Maher S. Design and Evaluation of Video Podcasts for Providing Online Feedback on Formative Pharmaceutical Calculations Assessments. American Journal of Pharmaceutical Education. 2017;81(10):6400. doi:10.5688/ajpe6400.

8. Eib BJ, Miller P. Faculty Development as Community Building - An approach to professional development that supports Communities of Practice for Online Teaching. The International Review of Research in Open and Distributed Learning. 2006;7(2). doi:10.19173/irrodl.v7i2.299

9. Wenger, Etienne, Richard A. McDermott, and William Snyder. 2002. Cultivating communities of practice: a guide to managing knowledge. Boston, Mass: Harvard Business School Press.

10. Potratz P. Want To Be Heard? 11 Crucial Tips For Starting A Podcast. Forbes. https://www.forbes.com/sites/paulpotratz/2018/07/ 12/want-to-be-heard-heres-11-necessary-tips-forstarting-a-podcast/\#fca86a252904. Published July 12, 2018. Accessed May 25, 2019. 
Table 1. Application of Seven Principles of Cultivating a Community of Practice ${ }^{8}$

Steps

Design for evolution
1. Identified goals

2. Designed initial framework of the podcast

3. Researched similar and aspirational podcasts

4. Established technical details and framework

Open a dialogue between inside and outside perspective

Invite different levels of participation

Develop both public and private community spaces

Focus on value

Combine familiarity and excitement
1. Connected with key stakeholders and potential audience members

2. Invited initial podcast guests

1. Established connection with AACP LDSIG Executive Committee

1. Created Twitter account

2. Disseminated content on AACP Connect

3. Requested feedback from audience members

1. Incorporated themes requested from audience members

2. Ensured themes met identified goals of the podcast

3. Included episode themes that tied directly into AACP LDSIG endeavors

1. Featured guests with established connections to AACP LDSIG

2. Incorporated episodes with guests outside of AACP that could speak on different leadership development topics
July 2018-August

2018

Timeline

September 2018

September 2018

September 2018-

November 2018

November 2018

December 2018

1. Created episodes in consistent format

2. Released episodes on a regular schedule 
Table 2. Select LDPEcast Episodes

\begin{tabular}{|c|c|c|}
\hline Select Episodes & Topic & $\begin{array}{l}\text { Connection to } \\
\text { LDSIG }\end{array}$ \\
\hline $\begin{array}{l}\text { A Relational Approach to } \\
\text { Leadership }\end{array}$ & $\begin{array}{l}\text { Relational and longitudinal approach } \\
\text { to leadership }\end{array}$ & $\begin{array}{l}\text { SIG Virtual } \\
\text { Symposium }\end{array}$ \\
\hline $\begin{array}{l}\text { Genesis of the Virtual } \\
\text { Symposium }\end{array}$ & $\begin{array}{l}\text { The Creation of the Virtual } \\
\text { Symposium }\end{array}$ & $\begin{array}{l}\text { SIG Virtual } \\
\text { Symposium }\end{array}$ \\
\hline The Culture Code & $\begin{array}{l}\text { Book review of The Culture Code by } \\
\text { Dan Coyle }\end{array}$ & Book Review \\
\hline $\begin{array}{l}\text { Mind of a Manager, Soul of a } \\
\text { Leader }\end{array}$ & $\begin{array}{l}\text { Book review of Mind of a Manager, } \\
\text { Soul of a Leader by Craig Hickman }\end{array}$ & Book Review \\
\hline $\begin{array}{l}\text { Formal Leadership Development } \\
\text { Series Part } 1\end{array}$ & $\begin{array}{l}\text { Perspective on residency leadership } \\
\text { development training }\end{array}$ & $\begin{array}{l}\text { Audience } \\
\text { Suggested Topic }\end{array}$ \\
\hline $\begin{array}{l}\text { Formal Leadership Development } \\
\text { Series Part } 2\end{array}$ & $\begin{array}{l}\text { Perspective of student leadership } \\
\text { development training }\end{array}$ & $\begin{array}{l}\text { Audience } \\
\text { Suggested Topic }\end{array}$ \\
\hline $\begin{array}{l}\text { Mentorship Series: Reflections } \\
\text { from Brett Kelly }\end{array}$ & Different views on mentorship & $\begin{array}{l}\text { Audience } \\
\text { Suggested Topic }\end{array}$ \\
\hline $\begin{array}{l}\text { Leadership Development: The } \\
\text { Great Escape }\end{array}$ & $\begin{array}{l}\text { Game-based learning and interplay } \\
\text { with leadership }\end{array}$ & $\begin{array}{l}\text { SIG Virtual } \\
\text { Symposium }\end{array}$ \\
\hline $\begin{array}{l}\text { Keynote Interview: Pharmacy } \\
\text { Leadership and a Historical } \\
\text { Perspective }\end{array}$ & $\begin{array}{l}\text { AACP keynote speaker and historical } \\
\text { author, Doris Kearns Goodwin's } \\
\text { perspectives on leadership }\end{array}$ & $\begin{array}{l}\text { Outside } \\
\text { Perspective }\end{array}$ \\
\hline
\end{tabular}

LDSIG: Leadership Development Special Interest Group 